\title{
Adolescent-to-Parent Violence: Psychological and Family Adjustment
}

\author{
Dolores Seijo', María J. Vázquez², Raquel Gallego ${ }^{3}$, Yurena Gancedo ${ }^{1}$ and \\ Mercedes Novo ${ }^{1 *}$
}

' Psicología Organizacional, Jurídica Forense y Metodología de las Ciencias del Comportamiento, Facultad de Psicología, University of Santiago de Compostela, Santiago de Compostela, Spain, ${ }^{2}$ Facultad de Ciencias de la Educación y del Trabajo Social, University of Vigo, Ourense, Spain, ${ }^{3}$ Unidad de Psicología Forense, Facultad de Psicología, University of Santiago de Compostela, Santiago de Compostela, Spain

Adolescent-to-Parent Violence (APV) or Child-to-Parent Violence (CPV) is a specific form of violence that has remained inconspicuous until recently, but is becoming a mounting social issue and is increasingly the focus of scientific research. Of the variables related to APV, the study assessed the characteristics of the family system and its relationship to the psychosocial adjustment of adolescents, an aspect scarcely examined in the literature. Thus, a field study was performed on a community sample of 210 adolescents aged 12-17 years (51.4\% girls) who were assessed on measurements of APV, parenting (parental socialization), victimization, and psychological adjustment (personal, family, and school). The results revealed higher rates of psychological APV, and no gender effects in violence exercised against either parent. The adolescents involved

OPEN ACCESS

Edited by:

Lourdes Contreras,

University of Jaén, Spain

Reviewed by:

Ana M. Martín,

University of La Laguna, Spain Francisco Javier Rodríguez Díaz,

University of Oviedo, Spain

*Correspondence: Mercedes Novo mercedes.novo@usc.es

Specialty section:

This article was submitted to Forensic and Legal Psychology, a section of the journal Frontiers in Psychology

Received: 17 June 2020 Accepted: 27 October 2020 Published: 25 November 2020

Citation:

Seijo $D$, Vázquez MJ, Gallego R, Gancedo Y and Novo M (2020) Adolescent-to-Parent Violence: Psychological and Family Adjustment.

Front. Psychol. 11:573728.

doi: 10.3389/fpsyg.2020.573728 in APV exhibited a greater psychological maladjustment in the different areas under analysis. Moreover, adolescents engaging in psychological APV reported a parental socialization style characterized by severe strictness and supervision in comparison to non-aggressors not implicated in psychological APV. Finally, adolescents exercising APV who were victimized by their parents showed more psychological, personal, and school maladjustment. These results have implications for needs analysis and the planning of community prevention strategies.

Keywords: adolescent-to-parent violence, parenting style, family system, maladjustment, victimization, childcare

\section{INTRODUCTION}

Antisocial behavior is a key issue in the field of Legal and Forensic Psychology (Arce et al., 2011). One of its expressions is adolescent-to-parent violence (APV, also known as child-to parent violence), a specific form of violence that has remained inconspicuous for decades (Ibabe, 2019), but was brought into the limelight in recent years owing to the rise in the number of cases and the severe impact on the entire family system (Holt, 2016; Del Hoyo-Bilbao et al., 2020). Owing to the social and legal involvements involved, the international scientific community is gradually shifting its focus toward this phenomenon but the number of specific APV studies still remains scarce (Gámez-Guadix and Calvete, 2012; Lyons et al., 2015). A recent systematic review (Simmons et al., 2018) has highlighted that the variations in the samples employed in previous studies and the plurality of definitions and measurements accounted for the discrepancies reported in the scientific literature (Gallego et al., 2019; Cortina and Martín, 2020; Loinaz and de Sousa, 2020).

According to the definition of APV, the data available on world prevalence rates revealed variations ranging from 5 to $21 \%$ for physical violence and higher rates of 33-93\% 
for psychological violence (Simmons et al., 2018). In Spain, most field studies have estimated prevalence rates of $21 \%$ for physical violence (Ibabe et al., 2013; Calvete et al., 2014; Ibabe and Bentler, 2016), and rates of $33-93 \%$ for psychological and emotional violence (Calvete et al., 2013; Ibabe, 2015; Ibabe and Bentler, 2016; Cortina and Martín, 2020). This high variability suggests the existence of moderators underlying the relationship. Thus, prevalence rates depend on the sample employed, with boys vastly outnumbering girls in judicial samples (Armstrong et al., 2018) by around 59-87\% (Simmons et al., 2018), whereas in normalized student or community samples, gender differences almost vanished (Loinaz et al., 2020). In relation to the type, violence, physical, or psychological, most of the studies on community and student samples found no significant gender differences in APV (Loinaz et al., 2020), whereas other studies reported girls exercised more psychological violence (Calvete et al., 2013; Rosado et al., 2017). In clinical and judicial samples, physical violence was mainly exercised by boys (Armstrong et al., 2018; Cortina and Martín, 2020), owing to the seriousness of the APV offense, this entailed a higher probability of custodial sentences, whereas girls were mainly involved in psychological violence. Nevertheless, other studies have found that girls in custody can also resort to severe forms of APV involving physical violence (Condry and Miles, 2014; Simmons et al., 2018).

Regarding the victims, several studies have shown mothers are more often the target of APV than fathers (Edenborough et al., 2008; Condry and Miles, 2014; Lyons et al., 2015) whilst other studies have found no significant differences between either parent (Loinaz et al., 2020), particularly in long-term violence (Calvete et al., 2013). Gender differences have also been related to types of violence, physical or psychological, with most physical violence being exercised by boys (Simmons et al., 2019), whereas mothers tend to be the target of psychological violence (Ibabe and Jaureguizar, 2010).

Family variables have gradually became the focus of research (Loinaz et al., 2018; Beckmann, 2020; Del Hoyo-Bilbao et al., 2020). Parenting styles have been linked to APV (Maccoby and Martin, 1983), in particular with authoritarian parenting styles in community and judicial samples, and a permissive parenting style in community, clinical, and offender samples (Simmons et al., 2018). Whereas parenting style is a key factor in the child's evolutionary process, during adolescence, it is crucial as it decisively influences attitudes and behavior (Cutrín et al., 2018). Research on the impact of different socialization styles has identified several factors linked to an adolescent's adaptation. Whereas a democratic style predicted greater psychosocial development, self-esteem, and academic achievement (Ibabe, 2015), an authoritarian, permissive, or neglectful style had negative outcomes for adolescents such as somatic symptoms, emotional stress, and antisocial and/or deviant behavior (Lamborn et al., 1991; Contreras and Cano, 2014; Ibabe, 2015; Suárez-Relinque et al., 2019). The influence of parenting styles on antisocial behavior have identified poor supervision and discipline as a crucial risk factor for this type of behavior in adolescence (Perez-Gramaje et al., 2020). The parents of APV adolescents were reluctant to impose discipline when children misbehaved, and showed lower levels of affect and support (Gámez-Guadix et al., 2012; Ibabe et al., 2013; Calvete et al., 2015). Recent studies support the relevance of affection and attachment in family relations (Beckmann et al., 2017; Curtis et al., 2019; Suárez-Relinque et al., 2019) with girls and boys who failed to receive affection adopting inappropriate problem-solving strategies, including APV (Gámez-Guadix et al., 2012; Cortina and Martín, 2020), whilst boys and girls exposed to coercive parental behavior appear to be at an increased risk of developing behavioral problems (Pasalich et al., 2011). Complementarily, several empirical studies have shown that affective warmth, emotional nurturance, and support giving were protective factors against the risk of violent behavior in children and adolescents (Jiménez-García et al., 2019; Suárez-Relinque et al., 2019; Cortina and Martín, 2020).

Furthermore, numerous studies on direct and vicarious victimization in childhood as a precipitator of APV have underscored the hypothesis of bidirectionality, i.e., parentsto-child violence predict child-to-parent violence (Routt and Anderson, 2011; Contreras and Cano, 2016; Del Hoyo-Bilbao et al., 2020). In a recent meta-analysis, Gallego et al. (2019) concluded that the probability of developing APV among adolescents victimized by their parents was $71 \%$ higher than in non-victimized adolescents under different conditions (community or judicial population, type of violence: physical or psychological, and type of victimization: direct or vicarious). Though bidirectionality has been well established, the same cannot be said of the adjustment in each of the significant areas of adolescents engaged in APV who were victimized by their parents (Haw, 2010; Novo et al., 2019; Contreras et al., 2020).

Thus, the aims of this study on the family system of adolescents engaged in APV were threefold: (1) to evaluate the personal and school psychological adjustment of adolescents involved in APV; (2) to assess parenting (parental socialization styles) as informed by the self-reports of APV and nonAPV adolescents; and (3) to compare psychosocial adjustment in victimized adolescents and victimized adolescents who also engaged in APV.

\section{MATERIALS AND METHODS}

\section{Participants}

A total of 210 adolescents, age range $12-17$ years $(M=13.21$, $S D=0.94$ ), from secondary schools in Galicia (Spain), participated in this study. The sample was balanced in terms of gender (107 girls, $51.4 \%) \chi^{2}(1)=0.08, n s$. As for the family structure informed by the participants, $79 \%$ were intact families and $17.7 \%$ were modifications to the original family unit, the main reasons were parental separation or divorce $(14.8 \%)$, work $(1.9 \%)$, or death $(0.9 \%)$. In relation to schooling, $13 \%$ were first, 20\% were second, and 67\% were third-year Compulsory Secondary Education students.

\section{Measurement Instruments}

For measuring APV, the Conflict Tactics Scale: Parent-Child Version (CTS-PC) (Straus and Fauchier, 2007) was administered. The instrument consists of six items, three for measuring physical 
violence (e.g., I slapped or punched my father/mother) and three for psychological violence (e.g., I shouted at my mother/father), answered on a three-point Likert response scale from never (0) to often (2) referring to the last year. The CTS-PC is an adapted version of the CTSCP scale but the directionality of the behavior has been modified. The response format is in line with the original scale, taking as a reference period the previous year. The reliability (Cronbach's alpha) of the scale was 0.63 for mothers and 0.59 for fathers.

The adjustment of the adolescents was evaluated using the Spanish adaptation of the Children and Adolescents Behavior Evaluation System (González et al., 2004) S3 selfreport. This instrument evaluates several aspects of behavior and personality, including both positive (adaptive) and negative (clinical) dimensions. The questionnaire comprises 14 scales grouped into clinical and adaptive scales. Moreover, it includes an F Index (measuring the negative tendency to respond negatively to adolescent behavior) an L Index (tendency for the adolescent to respond too positively), a Response Consistency Index, and a Response Pattern Index. As for the reliability of the scales, internal consistency was estimated to range from 0.70 to 0.90 .

The Parental Socialization Scale in Adolescence ESPA-29 (Escala de Socialización Parental en la Adolescencia ESPA-29; Musitu and García, 2001) was employed to assess parental socialization styles. This scale evaluates parental socialization styles in different representative scenarios. Children evaluate their father and mother separately in 29 situations. As for the procedure, 13 of the 29 situations are evaluated with the affect and indifference subscales. The remaining 16 situations are evaluated by the dialogue subscale ("speak to me"), neglect subscale ("s/he doesn't care"), psychological strictness subscale ("s/he tells me off"), physical strictness subscale ("s/he hits me"), and privation subscale ("I'm not allowed something"). Each scale has a 4-point scoring format (1, never; 2, sometimes; 3 , often; and 4, always). The score for the Acceptance/Involvement dimension is obtained from the dialogue, affect, and neglect subscales, whereas the score of the Strictness/Supervision dimension was calculated as the mean of the mean scores of the strictness, psychological strictness, and privation subscales. Internal consistency (Cronbach's alpha) was of 0.97 for the Acceptance/Involvement dimension, and of 0.96 for Strictness/Supervision.

For measuring victimization, the Parent-Child Conflict Tactics Scales (CTSPC) (Straus et al., 1998) was administered. This scale consists of six items measuring the frequency to which children suffer physical and/or psychological abuse from their parents, with a three-point response format: 0 (never), 1 (sometimes), and 2 (often). Each item is responded twice, one referring to the mother and the other, the father. In the present study, the internal consistency of the scale was an $\alpha$ of 0.83 for the father and an $\alpha$ of 0.78 for the mother.

\section{Procedure and Design}

A filed study with a community sample was designed to quantify the prevalence of APV, the deviation from normativity of child-to parent offenders in personal and school psychological adjustment; the mean comparison between offenders and non-offenders in parental socialization styles; the association between parent-to child violence and child-to parent violence; and the effects of parentto child victimization in the psychological, personal, and school and adjustment.

A community sample was gathered by accidental sampling from public schools in Galicia (northwest of Spain). In all schools, informed consent was obtained from the parents and tutors of the adolescents prior to inclusion in the study.

Participants were administered the questionnaires in two sessions in small groups in their usual classrooms. Participants were assured their data would remain anonymous and confidential in accordance with the Spanish data protection law (Ley Orgánica 3/2018 de Protección de Datos Personales y Garantía de los Derechos Digitales).

\section{Data Analysis}

Contingency tables were used to summarize the categorical variables, and the chi-square test was ran to analyze statistical differences. For the continuous variables, the comparison of the means between groups was performed using the Student's $t$-test for independent samples. The magnitude of the effect sizes was interpreted in terms of the Probability of Superiority of the Effect Size (PSES; Monteiro et al., 2018), a quantitative estimate of the effect-size i.e., probability of the superiority of the observed effect size in relation to all possible.

The identification of cases of adolescents who had exercised APV was in accordance with the "Zero tolerance" criterion enshrined in law and the directives of internationally recognized institutions and bodies such as the European Parliament Resolution on Zero Tolerance (Recommendation A4-0250/97, Resolution 2017/2897). In order to apply this criterion, participants were classified according to the CTS-PC Scale responses into individuals who had committed APV (raw score $\geq 1$ ) vs. those who had not (raw score $=0$ ).

\section{RESULTS}

\section{Frequency}

The analysis of the frequency of APV according to typology (i.e., psychological or physical), and the parent's gender revealed that psychological violence was employed both toward the mother (108 adolescents, 51.4\%) and the father (109 adolescents, $51.9 \%$ ), whereas the frequency of physical violence was $1.9 \%$ (4) for both parents. The results showed no gender differences between girls and boys in physical and psychological violence toward either parent, father, and mother alike (see Tables 1, 2).

\section{Personal and School Psychological Adjustment}

Thereafter, the psychological, personal, and school adjustment of adolescents engaged in growing violence in different significant spheres and/or areas was analyzed. Thus, the variable (APV vs. no APV) was recoded according to the "Zero tolerance" criterion 
TABLE 1 | Independent-samples t-test on type of violence against parent for the factor aggressor's gender (boy vs. girl).

\begin{tabular}{|c|c|c|c|c|c|c|c|}
\hline Variable & $t$ & $p$ & $M_{M}$ & $S D_{M}$ & $M_{F}$ & $S D_{F}$ & $d\left(\mathrm{PS}_{E S}\right)$ \\
\hline APV psychological father & 0.35 & 0.806 & 1.32 & 1.37 & 1.25 & 1.48 & $0.00(0.000)$ \\
\hline
\end{tabular}

df(128); $M_{M}$, mean of the boys' group in APV; $S D_{M}$, standard deviation of the boys' group; $M_{F}$, mean of the girls' group in APV; $S D_{F}$, standard deviation of the girls' group; d, Cohen's; PS ES, Probability of Superiority of the Effect Size.

TABLE 2 | Independent-samples $t$-test on type of violence against the mother for the factor aggressor's gender (boy vs. girl).

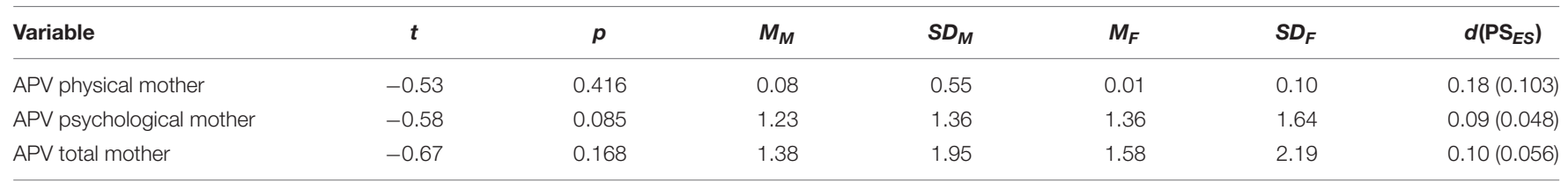

df(128); $M_{M}$, mean of the boys' group in APV; $S D_{M}$, standard deviation of the boys' group; $M_{F}$, mean of the girls' group in $A P V ; S D_{F}$, standard deviation of the girls' group; d, Cohen's; $P S_{E S}$, Probability of Superiority of the Effect Size.

TABLE 3 | One sample $t$-tests of psychological APV toward mother on BASC dimensions.

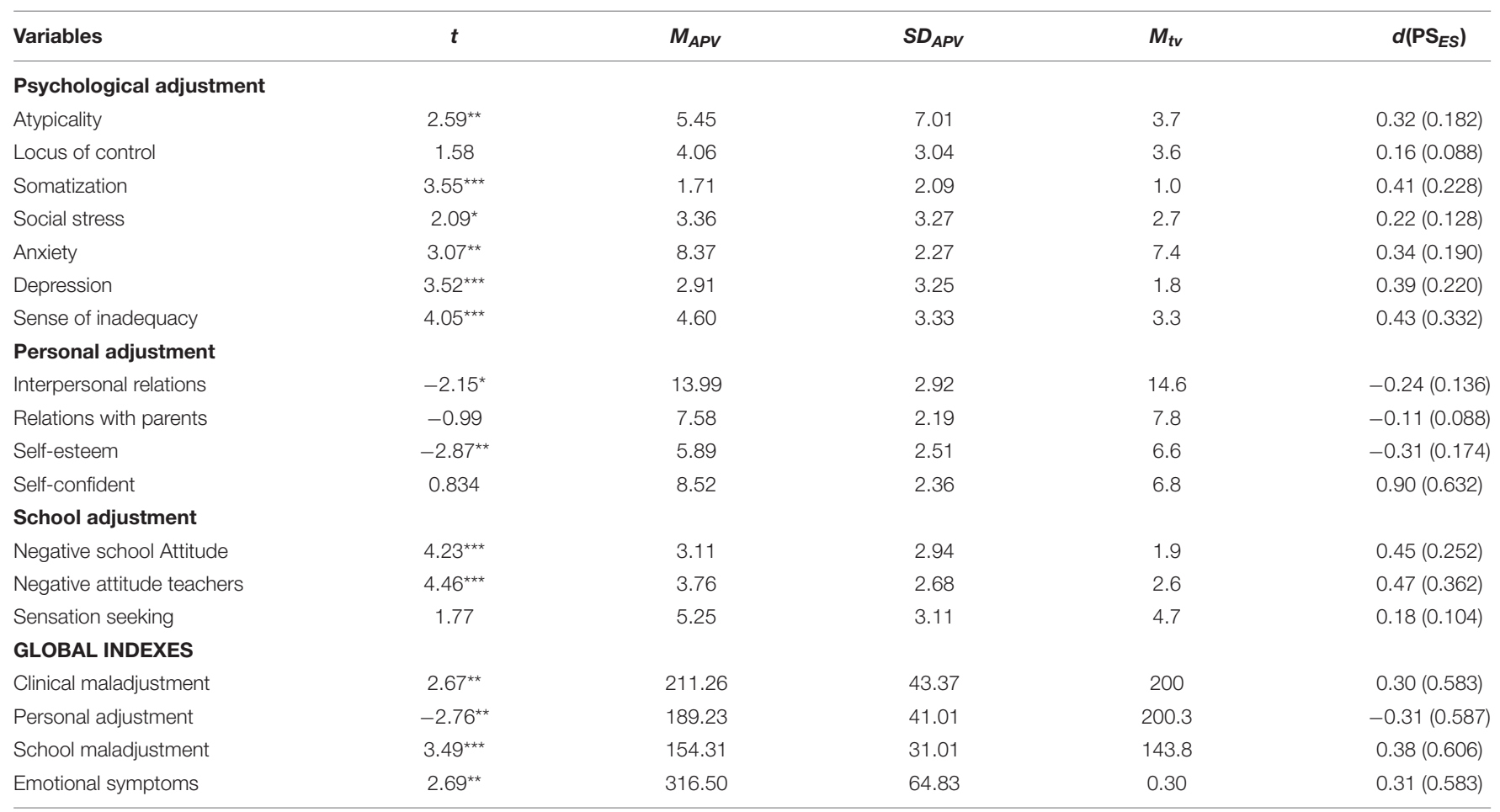

df(107); $M_{A P V}$, mean of the APV group; $S D_{A P V}$, standard deviation of the APV group; $M_{t V}$, test value (mean of the normative sample); $d$, Cohen's $d$; PS $E S$, Probability of Superiority of the Effect Size. ${ }^{* * *} p<0.001,{ }^{* *} p<0.01,{ }^{*} p<0.05$.

(see section "Data Analysis"), with a total of 109 adolescents (51.9\%) self-reporting growing psychological violence toward the father and 108 (51.4\%) toward the mother. In relation to physical APV, four adolescents (1.9\%) informed of violence toward the father and/or mother.

After recoding the psychological violence variable, the scores obtained by participants on the BASC scales were contrasted with the test value, i.e., the mean of the normative sample being obtained from the scoring manual of the instrument (González et al., 2004; Table 3).
As shown in Table 3, in relation to psychological adjustment, adolescents engaged in psychological APV toward the mother scored significantly higher than the normative population in Atypicality, Somatization, Social stress, Anxiety, Depression, and Sense of inadequacy, as well as on the global Clinical maladjustment index, with greater maladjustment in all of the scales assessed. As for personal adjustment, significant differences were found in the Interpersonal relations, and Selfesteem scales and their global indexes, with low adjustment values for adolescents exercising growing violence. As for the 
school area, the results were significant in the Negative attitude toward teachers, Negative attitude toward school scales, and global School Maladjustment index, revealing APV adolescents exhibited more hostile resentment or dissatisfaction toward school and teachers as compared to the normative population. The probability of superiority of the effect sizes for the statistical significance results (see Table 3) ranged from 36.2\% (Negative attitudes toward teachers) to $12.8 \%$ (Social stress) i.e., the magnitude of the effect size is greater than $34.8-12.8 \%$ of all possibilities.

Adolescents involved in psychological APV toward the father showed a significantly higher psychological maladjustment as compared to the normative population on the Atypicality, Somatization, Social stress, Anxiety, Depression, Sense of inadequacy scales, and global index of Clinical maladjustment. As for the area of Personal adjustment, Self-esteem and Interpersonal relations, and the global index of Personal adjustment revealed significant differences, with adolescents engaged in growing violence showing a lower self-esteem and higher personal maladjustment. In terms of school, APV adolescents scored significantly higher on the Negative attitude toward teachers, Negative attitude toward school scales, and School maladjustment index, with more hostile thoughts and a generalized rebuff toward the school, teachers, and structure of education. The magnitude of the statistically significant effect sizes (see Table 4) ranged from 34.8\% (Negative attitudes toward teachers) to $12.8 \%$ (Social stress) i.e., the magnitude of the effect size is greater than $34.8-12.8 \%$ of all possibilities.

\section{Parental Socialization Styles}

The results showed that adolescents engaging in psychological APV toward the mother (see Table 5) informed of a parental socialization style characterized by little Affect and much Indifference, in comparison to a non-aggressor not engaging in psychological APV. The global dimensions of Acceptance/Involvement and Strictness/Supervision were significant, with Acceptance/Involvement being lower in APV adolescents as compared to non-aggressors; and higher on the Strictness/Supervision scale. The effect sizes of each of the global dimensions were small. In relation to the father, only the Strictness/Supervision dimension was statistically significant, with higher scores in adolescents involved in growing violence, than in non-aggressors. Nevertheless, the magnitude of the probability of superiority of the effect was small: $19.6 \%$ for affect, $19.8 \%$ for indifference; $19.0 \%$ for acceptance/involvement, and $17.4 \%$ for strictness/supervision.

\section{Experience of Child Victimization}

APV and victimization variables were recorded in line with the previously mentioned "Zero tolerance" criterion to create only one variable, "adolescents engaged in APV," with values 0 (absence of APV) and 1 (presence of APV). The results of this classification showed that 121 participants (57.6\%) reported an instance of violent behavior toward parents in the last year vs. 73

TABLE 4 | One sample $t$-tests of psychological APV adolescents toward father on BASC dimensions.

\begin{tabular}{|c|c|c|c|c|c|}
\hline Variables & $t$ & $M_{A P V}$ & $S D_{A P V}$ & $M_{t v}$ & $d\left(\mathrm{PS}_{E S}\right)$ \\
\hline \multicolumn{6}{|l|}{ Psychological adjustment } \\
\hline Atypicality & $2.72^{\star \star}$ & 5.50 & 6.91 & 3.7 & $0.33(0.182)$ \\
\hline Locus of control & 1.60 & 4.05 & 2.95 & 3.6 & $0.00(0.000)$ \\
\hline Somatization & $3.32^{\star \star \star}$ & 1.62 & 1.96 & 1.0 & $0.37(0.206)$ \\
\hline Social stress & $2.02^{\star}$ & 3.34 & 3.30 & 2.7 & $0.22(0.128)$ \\
\hline Anxiety & $2.88^{\star *}$ & 8.28 & 3.19 & 7.4 & $0.27(0.150)$ \\
\hline Depression & $3.56^{\star \star \star}$ & 2.95 & 3.36 & 1.8 & $0.39(0.304)$ \\
\hline Sense of inadequacy & $4.67^{\star \star \star}$ & 4.78 & 3.30 & 3.3 & $0.49(0.376)$ \\
\hline \multicolumn{6}{|l|}{ Personal adjustment } \\
\hline Interpersonal relations & $-2.75^{\star \star}$ & 13.81 & 2.96 & 14.6 & $-0.30(0.236)$ \\
\hline Relations with parents & -1.28 & 7.52 & 2.20 & 7.8 & $-0.15(0.080)$ \\
\hline Self-esteem & $-2.93^{\star \star}$ & 5.87 & 2.54 & 6.6 & $-0.32(0.182)$ \\
\hline Self-confidence & 0.767 & 8.37 & 2.28 & 6.8 & $0.85(0.452)$ \\
\hline \multicolumn{6}{|l|}{ School adjustment } \\
\hline Negative attitude school & $4.51^{\star \star \star}$ & 3.10 & 2.76 & 1.9 & $0.46(0.258)$ \\
\hline Negative attitude teachers & $4.70^{\star \star \star}$ & 3.75 & 2.56 & 2.6 & $0.45(0.348)$ \\
\hline Sensation seeking & 1.32 & 5.10 & 3.15 & 4.7 & $0.13(0.072)$ \\
\hline \multicolumn{6}{|l|}{ Global indexes } \\
\hline Clinical maladjustment & $2.58^{\star}$ & 210.32 & 41.58 & 200.0 & $0.29(0.228)$ \\
\hline Personal adjustment & $3.16^{\star}$ & 187.33 & 42.55 & 200.3 & $-0.36(0.282)$ \\
\hline School maladjustment & $3.50^{\star \star \star}$ & 153.80 & 29.70 & 143.8 & $0.38(0.296)$ \\
\hline Emotional symptoms & $2.88^{\star \star}$ & 317.7 & 65.83 & 299.5 & $0.32(0.296)$ \\
\hline
\end{tabular}


TABLE 5 | Independent-samples t-test on parenting (parental socialization styles) for the factor psychological APV.

\begin{tabular}{|c|c|c|c|c|c|c|}
\hline Variables & $t$ & $M_{A P V}$ & $S D_{A P V}$ & $M_{n-A P V}$ & $S D_{n-A P V}$ & $d\left(\mathrm{PS}_{E S}\right)$ \\
\hline \multicolumn{7}{|l|}{ Mother $(n=173)$} \\
\hline Dialogue & 0.41 & 2.98 & 0.76 & 3.03 & 0.84 & $-0.06(0.032)$ \\
\hline Affect & $2.28^{\star}$ & 3.06 & 0.72 & 3.30 & 0.66 & $-0.35(0.196)$ \\
\hline Neglect & 1.85 & 1.26 & 0.40 & 1.15 & 0.33 & $0.30(0.166)$ \\
\hline Indifference & $2.36^{\star}$ & 1.64 & 0.75 & 1.39 & 0.62 & $0.36(0.198)$ \\
\hline Physical coercion & -1.75 & 1.13 & 0.48 & 1.03 & 0.30 & $0.25(0.142)$ \\
\hline Privation & -1.03 & 1.97 & 0.66 & 1.86 & 0.75 & $0.16(0.088)$ \\
\hline Psychological coercion & -1.90 & 2.71 & 0.65 & 2.50 & 0.75 & $0.30(0.166)$ \\
\hline Acceptance/Involvement & $2.23^{\star}$ & 3.26 & 0.47 & 3.42 & 0.46 & $-0.34(0.190)$ \\
\hline Strictness/Supervision & $-1.98^{\star}$ & 1.94 & 0.43 & 1.80 & 0.49 & $0.31(0.174)$ \\
\hline \multicolumn{7}{|l|}{ Father $(n=167)$} \\
\hline Dialogue & 0.57 & 2.81 & 0.79 & 2.87 & 0.78 & $-0.08(0.048)$ \\
\hline Affect & 0.89 & 2.99 & 0.71 & 3.08 & 0.69 & $-0.13(0.072)$ \\
\hline Neglect & -1.58 & 1.29 & 0.40 & 1.20 & 0.34 & $0.24(0.136)$ \\
\hline Indifference & -1.28 & 1.57 & 0.56 & 1.46 & 0.60 & $0.19(0.104)$ \\
\hline Physical coercion & -1.80 & 1.13 & 0.33 & 1.04 & 0.32 & $0.28(0.158)$ \\
\hline Privation & -1.36 & 1.91 & 0.623 & 1.78 & 0.66 & $0.20(0.112)$ \\
\hline Psychological coercion & -1.22 & 2.55 & 0.66 & 2.43 & 0.61 & $0.19(0.104)$ \\
\hline Acceptance/Involvement & 1.22 & 3.23 & 0.46 & 3.31 & 0.44 & $-0.18(0.104)$ \\
\hline Strictness/Supervision & $-2.21^{\star}$ & 1.88 & 0.43 & 1.74 & 0.40 & $0.34(0.190)$ \\
\hline
\end{tabular}

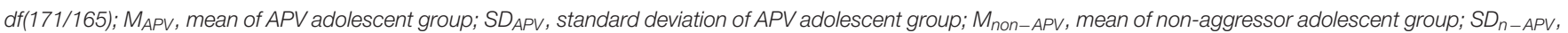
standard deviation of non-aggressor adolescent group; $d$, Cohen's $d$; PS $E S$, Probability of Superiority of the Effect Size. ${ }^{\star} P<0.05$.

(34.7\%) who had not and 16 (7.6\%), non-respondents. The same procedure was employed to quantify parent-to-child violence of participants to obtain only one variable of "victimization," with only two values 0 (absence of victimization) vs. 1 (presence of victimization). A total of 174 adolescents (82.8\%) reported an instance victimization, vs. 23 (10.9\%) adolescents reporting no victimization, and $13(6.1 \%)$ non-respondents. The results showed victimization was significantly associated to child-toparent violence, $\chi^{2}(1, N=174)=34.78, p<0.001$, that is, a relationship between being victimized by parents and being violent toward them, with a large effect size of $\varphi=0.426$ $\left(P S_{E S}=0.541\right.$, i.e., the effect is greater than $54.1 \%$ of all possible effects).

The results (see Table 6) revealed that victimized APV adolescents showed a higher maladjustment in the global indexes (Clinical maladjustment, higher School maladjustment, and lower Personal adjustment) with moderate magnitude effects sizes. Moreover, most of the scales in each of the areas under analysis were significant (except Anxiety, Interpersonal relations, and Negative attitude toward school and teachers), which indicated a greater maladjustment in victimized APV adolescents with a probability of superiority of the effect size from 39.8\% (Personal adjustment) to $22.8 \%$ (Somatization).

\section{DISCUSSION}

In this study on a community sample, APV was highly prevalent both toward the mother (51.4\%) and father (51.9\%), with negligible physical violence (1.9\%), which agreed with the findings of previous studies (Gámez-Guadix and Calvete,
2012; Ibabe et al., 2013; Aroca-Montolío et al., 2014; Calvete et al., 2015). Contrary to previous studies reporting higher rates of violence against mothers than fathers (Condry and Miles, 2014; Holt, 2016; Simmons et al., 2018), the results did not show differences between mothers and fathers for either the gender of the child or for the type of violence. Regarding this finding, some authors have proposed a link between the victim's gender and gender roles (Cottrell and Monk, 2004; Gallagher, 2004; Cortina and Martín, 2020). Thus, it is possible that the incorporation of women to the labor market, along with a dynamic flexible family model (Buehler, 2020), may contribute to a parity between mothers and fathers as victims (Williams et al., 2017). Furthermore, the blurring of gender roles in adolescents in comparison to traditional gender roles of the past may also play a key role.

As for the characteristics of adolescents involved in APV, no significant gender differences were observed. In general, there is no consensus in the literature regarding differences between boys and girls in exercising APV (Moulds and Day, 2017), with some studies reporting males perpetrate more violence than females (Ibabe et al., 2014; Calvete et al., 2015; Kuay et al., 2016), whereas others studies found no genders differences (Calvete et al., 2014; Margolin and Baucom, 2014; Bartle-Haring et al., 2015). The lack of consensus is associated to the type of samples employed, judicial or normalized. In this sense, the result of the present study corroborated the findings of previous studies in community samples where gender differences were blurred (Loinaz et al., 2020). Likewise, in the analysis of other types of violence related to adolescence, a number of studies have found no differences between boys and girls (Marcos et al., 2020), and 
TABLE 6 | Independent-samples $t$-test on the BASC dimensions for the factor victimization.

\begin{tabular}{|c|c|c|c|c|c|c|}
\hline Variables & $t$ & $M_{A P V}$ & $S D_{A P V}$ & $M_{n-A P V}$ & $S D_{n-A P V}$ & $d\left(\mathrm{PS}_{E S}\right)$ \\
\hline \multicolumn{7}{|l|}{ Adjustment psychological } \\
\hline Atypicality & $-2.53^{\star}$ & 4.87 & 3.53 & 3.08 & 3.18 & $0.51(0.282)$ \\
\hline Locus of control & $-2.13^{\star}$ & 3.98 & 2.78 & 2.82 & 2.35 & $0.45(0.252)$ \\
\hline Somatization & $-2.27^{\star}$ & 1.75 & 2.13 & 1.06 & 1.25 & $0.40(0.228)$ \\
\hline Social stress & $-2.13^{\star}$ & 3.26 & 3.16 & 1.91 & 2.79 & $0.45(0.348)$ \\
\hline Anxiety & -1.24 & 8.29 & 3.36 & 7.44 & 3.27 & $0.26(0.142)$ \\
\hline Depression & $-2.43^{\star}$ & 3.06 & 3.52 & 1.53 & 2.86 & $0.48(0.266)$ \\
\hline Sense of inadequacy & $-2.60^{*}$ & 4.82 & 3.09 & 3.20 & 2.88 & $0.54(0.296)$ \\
\hline \multicolumn{7}{|l|}{ Personal adjustment } \\
\hline Interpersonal relations & 0.98 & 14.00 & 2.56 & 14.50 & 2.07 & $-0.21(0.120)$ \\
\hline Relations with parents & $3.39^{\star \star \star}$ & 7.31 & 2.09 & 8.44 & 0.96 & $-0.69(0.376)$ \\
\hline Self-esteem & $2.63^{\star \star}$ & 5.85 & 2.59 & 6.97 & 1.80 & $-0.50(0.274)$ \\
\hline Self-confidence & $2.09^{\star}$ & 6.36 & 1.41 & 6.94 & 1.15 & $-0.45(0.252)$ \\
\hline \multicolumn{7}{|l|}{ School adjustment } \\
\hline Negative attitude school & -1.39 & 3.44 & 2.87 & 2.62 & 2.56 & $0.30(0.166)$ \\
\hline Negative attitude teachers & -1.45 & 4.09 & 2.68 & 3.27 & 2.76 & $0.32(0.182)$ \\
\hline Sensation seeking & $-2.23^{\star}$ & 5.28 & 3.39 & 3.79 & 2.84 & $0.48(0.266)$ \\
\hline \multicolumn{7}{|l|}{ Global indexes } \\
\hline Clinical maladjustment & $-2.67^{\star \star}$ & 212.5 & 38.88 & 195.2 & 28.21 & $0.51(0.282)$ \\
\hline Personal adjustment & $2.87^{\star \star}$ & 181.1 & 40.9 & 206.8 & 27.71 & $-0.74(0.398)$ \\
\hline School maladjustment & $-2.02^{\star}$ & 158.8 & 27.4 & 147.2 & 26.68 & $0.43(0.236)$ \\
\hline Emotional symptoms & $-2.46^{\star}$ & 322.4 & 58.9 & 293.0 & 48.83 & $0.54(0.304)$ \\
\hline
\end{tabular}

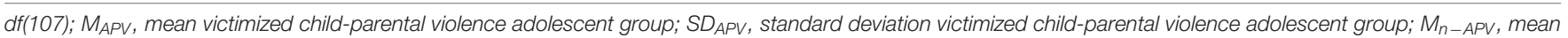

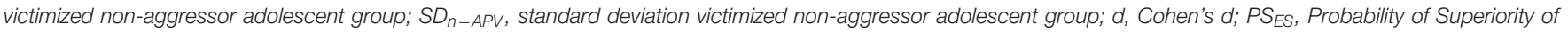
the Effect Size. ${ }^{* *} p<0.001,{ }^{* *} p<0.01,{ }^{*} p<0.05$.

have questioned the relevance of gender socialization in this particular phenomena.

Moreover, the results corroborated greater maladjustment in adolescents who engaged in psychological and/or physical violence toward their parents (Ibabe et al., 2013; Ibabe, 2014) in significant areas of functioning (e.g., psychological, personal, and school) of their lives (Seijo et al., 2016). Whether maladjustment causes violent behavior or inversely, the latter causes maladjustment, is an issue that goes beyond the scope of this study as the methodology was not designed to establish the causality of this relationship. Nevertheless, the findings underscored the need for multimodal and multilevel prevention, in accordance with the non-model approach (Arce et al., 2014; Basanta et al., 2018). Thus, it is of vital importance to determine the precise personal, family, and social needs for the psychological adjustment of adolescents involved in APV, and to estimate the magnitude in order to design and develop efficacious prevention programs and interventions (Mayorga et al., 2020).

The scientific literature has highlighted the importance of parenting in terms of parental socialization styles in generating and maintaining APV (Laurent and Derry, 1999; Cottrell and Monk, 2004; Contreras and Cano, 2014; Calvete et al., 2015; Suárez-Relinque et al., 2019). The loss of parental authority, lack of discipline and consistent norms, and poor affection and support were characteristics of families exposed to APV (Ibabe et al., 2013; Calvete et al., 2015). The results showed that adolescents engaged in APV reported higher levels of strictness and supervision both in paternal and maternal parenting. Furthermore, they reported more indifference and less affect, acceptance, and involvement in childrearing only in the maternal parenting style (Aroca-Montolío et al., 2012; Contreras and Cano, 2014; Calvete et al., 2015; Ibabe, 2015). The results corroborated the literature regarding the importance of mother positive parenting as a protective factor (Kawabata et al., 2011), however, they do not support this relationship for a father parenting style, giving more relevance to the mother's one. Furthermore, in accordance with the current approach of Positive Parenting of the Council of Europe (Council of Europe, 2006), the conception of traditional parenting associated to authority, discipline, and obedience should be replaced by the broader concept of parental responsibility (Fariña et al., 2017), which is particularly aimed at satisfying the needs of adolescents and safeguarding their rights and wellbeing, ensuring respect for parents, and analyzing specific parenting techniques and the quality of child parent relations (Simmons et al., 2018). In this way, the affectivity and quality of family relationships are essential to prevent the development and maintenance of APV (Contreras and Cano, 2014; Ibabe and Bentler, 2016; Beckmann et al., 2017; SuárezRelinque et al., 2019). Therefore, programs aimed at parental warmth are recommended (Bisby et al., 2017; Curtis et al., 2019).

The exposure to family violence as a variable linked to APV has been well documented in the literature (Ibabe et al., 2013; Loinaz et al., 2018). Recent studies have revealed that both direct and vicarious victimization were directly related to growing 
violence (Kennedy et al., 2010; Ibabe, 2015; Izaguirre and Calvete, 2017; Gallego et al., 2019). The results of the present study have corroborated this relationship with a large effect size. However, the results should be interpreted with caution given that the transversal design of this study was not designed to establish causal relations, and in spite of delimiting the temporal criterion of the previous year in applying the measures, it was impossible to determine the dynamics of violent relations if the violent behavior of adolescents was a reactive response to victimization or if the violent behavior of parents was a response to the violent behavior of adolescents (Brezina, 1999). Thus, APV should be assessed through the simultaneous analysis of growing violence and parent-to-child violence (Seijo et al., 2016), and growing violence as a predictor of parent-to-child violence (Gallego et al., 2019).

The presence of violent dynamics in the family should be considered a risk factor for the development of adolescents (Loinaz et al., 2018; Schmidt et al., 2018) and stifles and/or negatively influences the adjustment of adolescents in a range of significant areas of functioning. The results showed that adolescents who have suffered victimization and engaged in APV exhibited a higher psychological, personal, and school maladjustment (Castañeda et al., 2012; Ibabe, 2014; Rosado et al., 2017), in comparison to adolescents who did not exercise growing violence. According to several publications of the American Academy of Pediatrics, victimization in the family is considered to be an adverse childhood experience, a risk to health, and for the positive development of the adolescents (Garner et al., 2012; Exner-Cortens et al., 2013). As a toxic stress factor, it activates extreme and long lasting physiological responses to stress (Ecological and Biological Development Perspective). This exposure causes psychological injury and has negative implications on the physical and psychological development of adolescents (Garner et al., 2012; Exner-Cortens et al., 2013; Corrás et al., 2017).

Nonetheless, the results of the present study are subjected to limitations concerning generalizations: the sample size, transversal study design, and self-report of victimization may be biased by defensiveness-underreporting response bias (Harbin and Madden, 1979; Arce et al., 2015a). Further research to examine the different systems involved in APV (Cottrell and Monk, 2004), and to establish a measure of APV with clearly defined strict criteria is needed (Gallego et al., 2019). It is worth

\section{REFERENCES}

Arce, R., Fariña, F., and Novo, M. (2014). Competencia cognitiva en penados primarios y reincidentes: implicaciones para la reeducación [Cognitive competence among recidivist and non-recidivist prisoners: implications for the rehabilitation]. Ann. Psychol. 30, 259-266. doi: 10.6018/analesps.30.1.158201

Arce, R., Fariña, F., Seijo, D., and Novo, M. (2015a). Assessing impression management with the MMPI-2 in child custody litigation. Assessment 22, 769-777. doi: 10.1177/1073191114558111

Arce, R., Fariña, F., and Vilariño, M. (2015b). Daño psicológico en casos de víctimas de violencia de género: un estudio comparativo de las evaluaciones forenses [Psychological injury in intimate partner violence cases: a contrastive analysis of forensic measures]. Rev. Iberoamericana Psicol. Salud 6, 72-80. doi: 10.1016/ j.rips.2015.04.002 noting that none of the APV measurement instruments available evaluates recidivism that is a critical aspect, particularly in terms of psychological violence, the intent to cause harm, nor the injury caused (Arce et al., 2015b).

\section{DATA AVAILABILITY STATEMENT}

The raw data supporting the conclusions of this article will be made available by the authors, without undue reservation.

\section{ETHICS STATEMENT}

Ethical review and approval was not required for the study on human participants in accordance with the local legislation and institutional requirements. Written informed consent to participate in this study was provided by the participants' legal guardian/next of kin.

\section{AUTHOR CONTRIBUTIONS}

All authors have participated in the collection of the participants' data and managed their statistical treatment, and proceeded to the writing of the manuscript. DS, MN, and RG have directed all the work, participated in the interpretation and discussion of the data, as well as made interesting intellectual contributions in relation to the elaboration of the conclusions. Finally, all the signatories, one by one, have approved the final version of the manuscript for publication. Therefore, all authors are responsible and guarantee that all aspects that make up the manuscript have been reviewed and discussed among the authors in order to be exposed with the maximum precision and integrity.

\section{FUNDING}

This research has been partially sponsored by a grant of the Consellería de Cultura, Educación e Ordenación Universitaria of the Xunta de Galicia (ED431B 2020/46), and by a grant of the Spanish Ministry of Economy and Competitiveness (PSI201787278-R).

Arce, R., Fariña, F., and Vázquez, M. J. (2011). Grado de competencia social y comportamientos antisociales delictivos y no delictivos en menores [Social competence and delinquent, antisocial, and non-deviant behavior in adolescents]. Rev. Latinoamericana Psicol. 43, 473-486. doi: 10.14349/rlp.v4 $3 \mathrm{i} 3.487$

Armstrong, G. S., Cain, C. M., Wylie, L. E., Muftiæ, L. R., and Bouffard, L. A. (2018). Risk factor profile of youth incarcerated for child to parent violence: a nationally representative sample. J. Crim. Just. 58, 1-9. doi: 10.1016/j.jcrimjus.2018.06. 002

Aroca-Montolío, C., Bellver, M. C., and Alba, J. L. (2012). La teoría del aprendizaje social como modelo explicativo de la violencia filio-parental [The social learning theory as explicative model of child-parent violence]. Rev. Complut. Educ. 23, 487-511. doi: 10.5209/rev_RCED.2012.v23.n2. 40039 
Aroca-Montolío, C., Lorenzo-Moledo, M., and Miró-Pérez, C. (2014). La violencia filio-parental: un análisis de sus claves. Anal. Psicol. 30, 157-170. doi: 10.6018/ analesps.30.1.14952

Bartle-Haring, S., Slesnick, N., and Carmona, J. (2015). Reciprocity in adolescent and caregiver violence. J. Fam. Violence 30, 149-159. doi: 10.1007/s10896-0149659-5

Basanta, J., Fariña, F., and Arce, R. (2018). Risk-need-responsivity model: contrasting criminogenic and noncriminogenic needs in high and low risk juvenile offenders. Child. Youth Serv. Rev. 85, 137-142. doi: 10.1016/j. childyouth.2017.12.024

Beckmann, L. (2020). Family Relationships as risks and buffers in the link between parent-to-child physical violence and adolescent-to-parent physical violence. J. Fam. Violence 35, 131-141. doi: 10.1007/s10896-019-00048-0

Beckmann, L., Bergmann, M. C., Fischer, F., and Mößle, T. (2017). Risk and protective factors of child-to-parent violence: a comparison between physical and verbal aggression. J. Interpers. Violence 12, 1-26. doi: 10.1177/ 0886260517746129

Bisby, M. A., Kimonis, E. R., and Goulter, N. (2017). Low maternal warmth mediates the relationship between emotional neglect and callous-unemotional traits among male juvenile offenders. J. Child Fam. Stud. 26, 1790-1798. doi: 10.1007/s10826-017-0719-3

Brezina, T. (1999). Teenage violence toward parents as an adaptation to family strain: evidence from a national survey of male adolescents. Youth Soc. 30, 416-444. doi: 10.1177/0044118X99030004002

Buehler, C. (2020). Family processes and children's and adolescents' well-being. J. Marriage Fam. 82, 145-174. doi: 10.1111/jomf.12637

Calvete, E., Gámez-Guadix, M., and Orue, I. (2014). Características familiares asociadas a violencia filio-parental en adolescentes [Family characteristics associated with child-to-parent aggressions in adolescents]. Ann. Psychol. 30, 1176-1182. doi: 10.6018/analesps.30.3.166291

Calvete, E., Gámez-Guadix, M., Orue, I., González-Diez, Z., de Arroyabe, E. L., Sampedro, R., et al. (2013). Brief report: the adolescent child-to-parent aggression questionnaire: an examination of aggressions against parents in Spanish adolescents. J. Adolesc. 36, 1077-1081. doi: 10.1016/j.jadohealth.2013. 03.030

Calvete, E., Orue, I., Gamez-Guadix, M., and Bushman, B. J. (2015). Predictors of child-to-parent aggression: A 3-year longitudinal study. Dev. Psychol. 51, 663-676. doi: 10.1037/a0039092

Castañeda, A., Garrido-Fernández, M., and Lanzarote, M. D. (2012). Menores con conducta de maltrato hacia los progenitores: un estudio de personalidad y estilos de socialización. [Juvenile offenders who assault their parents: a study of personality traits and parenting styles]. Intern. J. Soc. Psychol. 27, 157-167. doi: $10.1174 / 021347412800337933$

Condry, R., and Miles, C. (2014). Adolescent to parent violence: framing and mapping a hidden problem. Criminol. Crim. Just. 14, 257-275. doi: 10.6018/ $10.1177 / 1748895813500155$

Contreras, L., and Cano, M. C. (2014). Adolescents who assault their parents: a different family profile of young offenders. Violence Vict. 29, 393-406. doi: 10.1891/0886-6708.VV-D-12-00132

Contreras, L., and Cano, M. C. (2016). Child-to-parent violence: the role of exposure to violence and its relationship to social-cognitive processing. Eur. J. Psychol. Appl. Legal Context 8, 43-50. doi: 10.1016/j.ejpal.2016.03.003

Contreras, L., León, S. P., and Cano-Lozano, M. C. (2020). Socio-cognitive variables involved in the relationship between violence exposure at home and childto-parent violence. J. Adolesc. 80, 19-28. doi: 10.1016/j.adolescence.2020.01. 017

Corrás, T., Seijo, D., Fariña, F., Novo, M., Arce, R., and Cabanach, R. G. (2017). What and how much do children lose in academic settings owing to parental separation? Front. Psychol. 8:1545. doi: 10.3389/fpsyg.2017.01545

Cortina, H., and Martín, A. M. (2020). The behavioral specificity of child-to-parent violence. Ann. Psychol. 36, 386-399. doi: 10.6018/analesps.411301

Cottrell, B., and Monk, P. (2004). Adolescent-to-parent abuse a qualitative overview of common themes. J. Fam. Issues 25, 1072-1095. doi: 10.1177/ 0192513 X03261330

Council of Europe (2006). Council of Europe Recommendation Rec(2006)19 on Policy to Support Positive Parenting. Available online at: https: //archive.crin.org/en/library/legal-database/council-europe-recommendationrec200619-policy-support-positive-parenting.html
Curtis, A., Harries, T., Moulds, L., and Miller, P. (2019). Addressing child-toparent violence: developmental and intervention considerations. J. Fam. Stud. doi: 10.1080/13229400.2019.1682643

Cutrín, O., Maneiro, L., Sobral, J., and Gómez-Fraguela, J. A. (2018). Longitudinal effects of parenting mediated by deviant peers on violent and non-violent antisocial behaviour and substance use in adolescence. Eur. J. Psychol. Appl. Legal Context 11, 23-32. doi: 10.5093/ejpalc2018a12

Del Hoyo-Bilbao, J., Orue, I., Gámez-Guadix, M., and Calvete, E. (2020). Multivariate models of child-to-mother violence and child-to-father violence among adolescents. Eur. J. Psychol. Appl. Legal Context 12, 11-21. doi: 10.5093/ ejpalc2020a2

Edenborough, M., Jackson, D., Mannix, J., and Wilkes, L. M. (2008). Living in the red zone: the experience of child-to-mother violence. Child Fam. Soc. Work 13, 464-473. doi: 10.1111/j.1365-2206.2008.00576.x

Exner-Cortens, D., Eckenrode, J., and Rothman, E. (2013). Longitudinal associations between teen dating violence victimization and adverse health outcomes. Pediatrics 131, 71-78. doi: 10.1542/peds.2012-1029

Fariña, F., Seijo, D., Arce, R., and Vázquez, M. J. (2017). Custodia compartida, corresponsabilidad parental y la Justicia Terapéutica como nuevo paradigma [Joint custody, parental co-responsibility, and Therapeutic Jurisprudence as a new paradigm]. Anuario Psicol. Juríd. 27, 107-113. doi: 10.1016/j.apj.2016.11. 001

Gallagher, E. (2004). Youth who victimise their parents. Austr. N. Zeal. J. Fam. Therapy 25, 94-105. doi: 10.1002/j.1467-8438.2004.tb00591.x

Gallego, R., Novo, M., Fariña, F., and Arce, R. (2019). Child-to-parent violence and parent-to-child violence: a meta-analytic review. Eur. J. Psychol. Appl. Legal Context 11, 51-59. doi: 10.5093/ejpalc2019a4

Gámez-Guadix, M., and Calvete, E. (2012). Violencia filioparental y su asociación con la exposición a la violencia marital y la agresión de padres a hijos [Child-to-parent violence and its association with exposure to marital violence and parent-to-child violence]. Psicothema 24, 277-283. doi: 10.2478/ 9788395609596-020

Gámez-Guadix, M., Jaureguizar, J., Almendros, C., and Carrobles, J. A. (2012). Estilos de socialización familiar y violencia de hijos a padres en población española [Parenting styles and child to parent violence in Spanish population]. Behav. Psychol. 20, 585-602.

Garner, A., Shonkoff, J., Siegel, B., Dobbins, M., Earls, M., McGuinn, L., et al. (2012). Early childhood adversity, toxic stress, and the role of the pediatrician: translating developmental science into lifelong health. Pediatrics 129, 224-231.

González, J., Fernández, S., Pérez, E., and Santamaría, P. (2004). Adaptación Española del Sistema de Evaluación de la Conducta en Niños y Adolescentes: BASC. Madrid: TEA.

Harbin, H., and Madden, D. (1979). Battered parents: a new syndrome. Am. J. Psychiatry 136, 1288-1291. doi: 10.1176/ajp.136.10.1288

Haw, A. (2010). Parenting Over Violence: Understanding and Empowering Mothers Affected by Adolescent Violence in the Home. Perth, WA: Department for Communities, Office for Women's Interests.

Holt, A. (2016). Adolescent-to-parent abuse as a form of "domestic violence": a conceptual review. Trauma Violence Abuse 17, 490-499. doi: 10.1177/ 1524838015584372

Ibabe, I. (2014). Efectos directos e indirectos de la violencia familiar sobre la violencia filio-parental [Direct and indirect effects of family violence on childto-parent violence]. Estud. Psicol. 35, 137-167. doi: 10.1080/02109395.2014. 893647

Ibabe, I. (2015). Predictores familiares de la violencia filio-parental. El papel de la disciplina familiar [Family predictors of child-to-parent violence: the role of family discipline]. Ann. Psychol. 31, 615-625. doi: 10.6018/analesps.31.2. 174701

Ibabe, I. (2019). Adolescent-to-parent violence and family environment: the perceptions of same reality? Intern. J. Environ. Res. Public Health 16, 2215-2228. doi: 10.3390/ijerph16122215

Ibabe, I., and Bentler, P. M. (2016). The contribution of family relationships to child-to-parent violence. J. Fam. Violence 31, 259-269. doi: 10.1007/s10896015-9764-0

Ibabe, I., and Jaureguizar, J. (2010). Child-to-parent violence: profile of abusive adolescents and their families. J. Crim. Just. 38, 616-624. doi: 10.1016/j.jcrimjus. 2010.04.034 
Ibabe, I., Jaureguizar, J., and Bentler, P. M. (2013). Protective factors for adolescent violence against authority. Span. J. Psychol. 16, 1-13. doi: 10.1017/sjp.2013.72

Ibabe, I., Arnoso, A., and Elgorriaga, E. (2014). Behavioral problems and depressive symptomatology as predictors of child-to-parent violence. Eur. J. Psychol. Appl. to Leg. Context 6, 53-61. doi: 10.1016/j.ejpal.2014.06.004

Izaguirre, A., and Calvete, E. (2017). Exposure to family violence as a predictor of dating violence and child-to-parent aggression in Spanish adolescents. Youth Soc. 49, 393-412. doi: 10.1177/0044118X16632138

Jiménez-García, P., Contreras, L., and Cano-Lozano, M. C. (2019). Types and intensity of postdivorce conflicts, the exercise of coparenting and its consequences on children. Rev. Iberoamericana Psicol. Salud 10, 48-63. doi: 10.23923/j.rips.2019.01.025

Kawabata, Y., Alink, L. R. A., Tseng, W., van Ijzendorrn, M. H., and Crick, N. R. (2011). Maternal and paternal parenting styles associated with relational aggression in children and adolescents: a conceptual analysis and meta-analytic review. Dev. Rev. 31, 240-278. doi: 10.1016/j.dr.2011.08.001

Kennedy, T., Edmonds, W., Dann, K., and Burnett, K. (2010). The clinical and adaptive features of young offenders with histories of child-parent violence. J. Fam. Violence 25, 509-520. doi: 10.1007/s10896-010-9312-x

Kuay, H., Lee, S., Centifanti, L., Parnis, A. C., Mrozik, J., and Tiffin, P. (2016). Adolescents as perpetrators of aggression within the family. Int. J. Law Psychiatry 47, 60-67. doi: 10.1016/j.ijlp.2016.02.035

Lamborn, S. D., Mounts, N. S., Steinberg, L., and Dornbusch, S. M. (1991). Patterns of competence and adjustment among adolescents from authoritative, authoritarian, indulgent, and neglectful families. Child Dev. 62, 1049-1065. doi: $10.2307 / 1131151$

Laurent, A., and Derry, A. (1999). Violence of French adolescents toward their parents: characteristics and contexts. J. Adolesc. Health 25, 21-26. doi: 10.1016/ s1054-139x(98)00134-7

Loinaz, I., Barboni, L., and de Sousa, A. M. (2020). Gender differences in child to parent violence risk factors. Ann. Psychol. 36, 408-417. doi: 10.6018/analesps. 428531

Loinaz, I., and de Sousa, A. M. (2020). Assessing risk and protective factors in clinical and judicial child-to-parent violence cases. Eur. J. Psychol. Appl. Legal Context 12, 43-51. doi: 10.5093/ejpalc2020a5

Loinaz, I., Marzabal, I., and Andrés-Pueyo, A. (2018). Risk factors of female intimate partner and non-intimate partner homicides. Eur. J. Psychol. Appl. Legal Context 10, 49-55. doi: 10.5093/ejpalc2018a4

Lyons, J., Bell, T., Fréchette, S., and Romano, E. (2015). Child-to-parent violence: frequency and family correlates. J. Fam. Violence 30, 729-742. doi: 10.1007/ s10896-015-9716-8

Maccoby, E. E., and Martin, J. A. (1983). "Socialization in the context of the family: parent-child interaction," in Socialization, Personality, and Social Development, ed. E. M. Hetherington (New York, NY: Wiley), 1-101.

Marcos, V., Gancedo, Y., Castro, B. Y., and Selaya, A. (2020). Dating violence victimization, perceived gravity in dating violence behaviors, sexism, romantic love myths and emotional dependence between female and male adolescents. Rev. Iberoamericana Psicol. Salud 11, 132-145. doi: 10.23923/j.rips.2020.02.040

Margolin, G., and Baucom, B. (2014). Adolescents' aggression to parents: longitudinal links with parents' physical aggression. J. Adolesc. Health 55, 645-651. doi: 10.1016/j.jadohealth.2014.05.008

Mayorga, E., Novo, M., Fariña, F., and Seijo, D. (2020). Estudio de las necesidades en el ajuste personal, social y psicológico en adolescentes en riesgo de delincuencia e infractores. Anal. Psicol. 36, 400-407. doi: 10.6018/analesps. 428631

Monteiro, A., Vázquez, M. J., Seijo, D., and Arce, R. (2018). ¿Son los criterios de realidad válidos para clasificar y discernir entre memorias de hechos autoexperimentados y de eventos vistos en vídeo? [Are the reality criteria valid to classify and to discriminate between memories of self-experienced events and memories of video-observed events?]. Rev. Iberoamericana Psicol. Salud 9, 149-160. doi: 10.23923/j.rips.2018.02.020
Moulds, L., and Day, A. (2017). Characteristics of adolescent violence towards parents: a rapid evidence assessment. J. Aggress. Conflict Peace Res. 9, 195-209. doi: 10.1108/JACPR-11-2016-0260

Musitu, G., and García, F. (2001). Parenting Socialization Scale in Adolescence. Madrid: TEA.

Novo, M., Fariña, F., Seijo, D., Vázquez, M. J., and Arce, R. (2019). Assessing the effects of a parental separation education program on mental health problems. Psicothema 31, 284-291. doi: 10.7334/psicothema2018.299

Pasalich, D. S., Dadds, M. R., Hawes, D. J., and Brennan, J. (2011). Do callous-unemotional traits moderate the relative importance of parental coercion versus warmth in child conduct problems? An observational study. J. Child Psychol. Psychiatry 52, 1308-1315. doi: 10.1111/j.1469-7610.2011.02435. $\mathrm{x}$

Perez-Gramaje, A. F., Garcia, O. F., Reyes, M., Serra, E., and Garcia, F. (2020). Parenting styles and aggressive adolescents: relationships with self-esteem and personal maladjustment. Eur. J. Psychol. Appl. Legal Context 12, 1-10. doi: 10.5093/ejpalc2020a1

Rosado, J., Rico, E., and Cantón-Cortés, D. (2017). Influence of psychopathology on the perpetration of child-to-parent violence: differences as a function of sex. Anal. Psicol. 33, 243-251. doi: 10.6018/analesps.33.2.240061

Routt, G., and Anderson, L. (2011). Adolescent violence towards parents. J. Aggress. Maltreat. Trauma 20, 1-19. doi: 10.1080/10926771.2011.537595

Schmidt, S., van der Meer, E., Tydecks, S., and Bliesener, T. (2018). How culture and migration affect risk assessment. Eur. J. Psychol. Appl. Legal Context 10, 65-78. doi: 10.5093/ejpalc2018a7

Seijo, D., Fariña, F., Corras, T., Novo, M., and Arce, R. (2016). Estimating the epidemiology and quantifying the damages of parental separation in children and adolescents. Front. Psychol. 7:1611. doi: 10.3389/fpsyg.2016.01611

Simmons, M., McEwan, T. E., Purcell, R., and Ogloff, J. R. (2018). Sixty years of child-to-parent abuse research: what we know and where to go. Aggress. Violent Behav. 38, 31-52. doi: 10.1016/j.avb.2017.11.001

Simmons, M. L., McEwan, T. E., Purcell, R., and Huynh, M. (2019). The abusive behaviour by children-indices (ABC-I): a measure to discriminate between normative and abusive child behaviour. J. Fam. Viol. 34, 663-676. doi: 10.1007/ s10896-019-00071-1

Straus, M., and Fauchier, A. (2007). Manual for the Dimensions of Discipline Inventory (DDI). Durham, NH: Family Research Laboratory, University of New Hampshire.

Straus, M., Hamby, S., Finkelhor, D., Moore, D., and Runyan, D. (1998). Identification of child maltreatment with the parent-child conflict tactics scales: development and psychometric data for a national sample of american parents. Child Abuse Negl. 22, 249-270. doi: 10.1016/S0145-2134(97)001 74-9

Suárez-Relinque, C., Arroyo, G. M., León-Moreno, C., Jerónimo, C., and Evaristo, J. (2019). Child-to-parent violence: which parenting style is more protective? A study with Spanish adolescents. Intern. J. Environ. Res. and Public Health 16, 1320-1333. doi: 10.3390/ijerph16081320

Williams, M., Tuffin, K., and Niland, P. (2017). "It's like he just goes off, BOOM!": mothers and grandmothers make sense of child-to-parent violence. Child Fam. Soc. Work 22, 597-606. doi: 10.1111/cfs. 12273

Conflict of Interest: The authors declare that the research was conducted in the absence of any commercial or financial relationships that could be construed as a potential conflict of interest.

Copyright $(2020$ Seijo, Vázquez, Gallego, Gancedo and Novo. This is an open-access article distributed under the terms of the Creative Commons Attribution License (CC BY). The use, distribution or reproduction in other forums is permitted, provided the original author(s) and the copyright owner(s) are credited and that the original publication in this journal is cited, in accordance with accepted academic practice. No use, distribution or reproduction is permitted which does not comply with these terms. 